\title{
Correction to: Mechanical stretching of the pulmonary vein mediates pulmonary hypertension due to left heart disease by regulating SAC/ MAPK pathway and the expression of IL- 6 and TNF- $a$
}

Wenhui Huang ${ }^{1,2}$, Hongjin Liu', Yichao Pan ${ }^{1}$, Hongwei Yang ${ }^{1}$, Jing Lin ${ }^{1}$ and Hui Zhang ${ }^{3 *}$

Correction to: J Cardiothorac Surg 16, 127 (2021)

https://doi.org/10.1186/s13019-021-01471-5

The original article [1] contained an incorrect designation of co-first authorship which has since been removed.

\section{Author details}

'Department of Cardiovascular Surgery, Union Hospital, Fujian Medical University, Fuzhou 350001, Fujian Province, People's Republic of China. ${ }^{2}$ Anesthesiology Research Institute, the First Affiliated Hospital, Fujian Medical University, Fuzhou 350004, Fujian Province, People's Republic of China.

${ }^{3}$ Department of Intensive Care Unit, Union Hospital, Fujian Medical University, Fuzhou 350004, Fujian Province, People's Republic of China.

Published online: 09 June 2021

\section{Reference}

1. Huang W, Liu H, Pan Y, Yang H, Lin J, Zhang H. Mechanical stretching of the pulmonary vein mediates pulmonary hypertension due to left heart disease by regulating SAC/ MAPK pathway and the expression of IL-6 and TNF-a. J Cardiothorac Surg. 2021;16(1):127. https://doi.org/10.1186/s13019021-01471-5.

The original article can be found online at https://doi.org/10.1186/s13019021-01471-5.

* Correspondence: fjxhzh2521@163.com

${ }^{3}$ Department of Intensive Care Unit, Union Hospital, Fujian Medical

University, Fuzhou 350004, Fujian Province, People's Republic of China

C C The Author(s). 2021 Open Access This article is licensed under a Creative Commons Attribution 4.0 International License, which permits use, sharing, adaptation, distribution and reproduction in any medium or format, as long as you give appropriate credit to the original author(s) and the source, provide a link to the Creative Commons licence, and indicate if changes were made. The images or other third party material in this article are included in the article's Creative Commons licence, unless indicated otherwise in a credit line to the material. If material is not included in the article's Creative Commons licence and your intended use is not permitted by statutory regulation or exceeds the permitted use, you will need to obtain permission directly from the copyright holder. To view a copy of this licence, visit http://creativecommons.org/licenses/by/4.0/ The Creative Commons Public Domain Dedication waiver (http://creativecommons.org/publicdomain/zero/1.0/) applies to the data made available in this article, unless otherwise stated in a credit line to the data. 